\title{
ESTUDO DA VIDA-DE-PRATELEIRA DE BEBIDA ELABORADA PELA MISTURA DE GARAPA PARCIALMENTE CLARIFICADA- ESTABILIZADA E SUCO NATURAL DE MARACUJÁ
}

\author{
PATRICIA PRATI * \\ ROBERTO HERMÍNIO MORETTI ** \\ HELENA MARIA ANDRÉ BOLINI CARDELLO *** \\ ANA LOURDES NEVES GÂNDARA ****
}

\begin{abstract}
O objetivo desta pesquisa foi estudar a vida-de-prateleira de produto elaborado com garapa, parcialmente clarificadaestabilizada, e suco de maracujá (5\%). A mistura foi adicionada de antioxidante, conservante e espessante em concentrações pré-estabelecidas. Após pasteurização, o produto foi resfriado, embalado em garrafas de polietileno tereftalato (PET) e armazenado sob refrigeração pelo período de um mês. Foram realizadas determinações microbiológicas (Contagem Padrão, Contagem de Bolores e Leveduras, Coliformes Totais e Fecais), físico-químicas $(\mathrm{pH}$, B Brix, acidez, relação Brix/Acidez, teor de ácido ascórbico, turbidez), e sensoriais. Os resultados da análise sensorial, considerados os mais relevantes para a pesquisa, indicaram que o produto (mistura de garapa parcialmente clarificadaestabilizada com suco de maracujá) pode ser elaborado e comercializado por até quinze dias sob refrigeração, pois as condições do processo permitiram a manutenção da qualidade microbiológica e sensorial. O teor de ácido ascórbico manteve-se em bom nível até o final da estocagem, com perda de apenas $20 \%$ em relação ao teor adicionado.
\end{abstract}

PALAVRAS-CHAVE: CANA-DE-AÇÚCAR; MARACUJÁ; SUCO DE FRUTA; ANÁLISE SENSORIAL.

* Doutoranda, Departamento de Tecnologia de Alimentos (DTA), Faculdade de Engenharia de Alimentos (FEA), Universidade de Campinas (UNICAMP), CampinasSP (e-mail: pprati00@yahoo.com).

** Professor Titular, DTA, FEA, UNICAMP, Campinas-SP (e-mail: moretti@fea.unicamp.br).

*** Professora Doutora, Departamento de Alimentos e Nutrição, Faculdade de Engenharia de Alimentos - UNICAMP, Campinas-SP (e-mail: hellini@fea.unicamp.br).

**** Microbiologista Pesquisadora, DTA, FEA, UNICAMP, Campinas-SP (e-mail: agandara@fea.unicamp.br). 


\section{INTRODUÇÃO}

A garapa ou caldo-de-cana constitui bebida muito apreciada no Brasil pelas suas características de refrescância e sabor doce. Nas grandes regiões produtoras de cana-de-açúcar (Sudeste e Nordeste) é muito comum a comercialização do produto por vendedores ambulantes, denominados de "garapeiros". Nos locais de clima quente, o caldo-decana servido gelado torna-se ainda mais atraente para o consumidor.

A comercialização da garapa adicionada de sucos de frutas ácidas como limão, abacaxi e maracujá (em pequenas proporções) tem por finalidade incrementar seu sabor e mascarar a doçura, muitas vezes excessiva.

O suco de maracujá tem conquistado espaço no mercado de sucos devido ao sabor exótico intenso, forte aroma (tipicamente tropical), elevada acidez e rendimento de polpa (GARRUTI, 1989). Tais características tornaram o suco de maracujá interessante para a elaboração de bebidas mistas de sucos de frutas, sorvetes, cremes e outros produtos de confeitaria (SOUZA e SANDI, 2001; MEDINA et al., 1980). Mesmo adicionado em pequenas proporções, o suco de maracujá é capaz de conferir seu aroma e sabor intenso em diversos produtos.

O surgimento de novos produtos no mercado pode estimular o desenvolvimento de pequenas agroindústrias existentes, aumentando seu potencial produtivo, e promover o aparecimento de outras empresas do ramo. Além disso, a elaboração de bebida tendo suco de maracujá como base pode reduzir as perdas da safra pelo aproveitamento do excedente da produção da fruta.

A presente pesquisa teve como objetivo estudar as características microbiológicas, físicas, químicas e sensoriais de misturas de garapa clarificada-estabilizada e suco natural de maracujá. As misturas foram adicionadas de antioxidante, conservador e espessante, sendo então pasteurizadas, acondicionadas em garrafas de polietileno tereftalato (PET) e armazenadas sob refrigeração durante um mês. 


\section{MATERIAL E MÉTODOS}

\subsection{MATERIAL}

\subsubsection{Matéria-Prima}

Utilizou-se caldo de cana-de-açúcar (Saccharum spp) da variedade RB72-454, empregada na comercialização de garapa na região de Piracicaba. Efetuou-se a extração em moenda elétrica (Modelo STN30 / 270 rpm) na Planta Piloto do Setor de Frutas, Hortaliças e Produtos Açucarados, Departamento de Tecnologia de Alimentos (DTA), Faculdade de Engenharia de Alimentos (FEA), Universidade de Campinas (UNICAMP).

O suco natural de maracujá-amarelo (Passiflora edulis f. flavicarpa) foi extraído, manualmente, no Laboratório de Frutas, Hortaliças e Produtos Açucarados do DTA, FEA/UNICAMP. A proporção do suco foi previamente estabelecida em $5 \%$ (5 mL de suco de maracujá / $100 \mathrm{~mL}$ de garapa).

\subsubsection{Outros Materiais}

Para o processo parcial de clarificação-estabilização do caldo-de-cana empregou-se policloreto de alumínio (PAC), do tipo "Panclar P-1010", como único agente químico de clarificação na concentração de 60 ppm.

Utilizou-se ácido ascórbico como antioxidante natural, cuja concentração de 125 ppm foi estabelecida por PRATI, MORETTI e CARDELLO (2002). Como conservador empregou-se o parabeno pelas vantagens que apresenta (LEITÃO, 1973; GAVA, 1984; FRANCO e LANDGRAF, 1996) e em concentração também pré-determinada (40 ppm).

Adicionou-se espessante para evitar a separação de fases na bebida durante o armazenamento, pois o suco de maracujá apresenta alto teor de polpa. Nesse caso, utilizou-se Pectina Genu tipo 106 na proporção pré-estabelecida de $0,05 \%$ (0,05 g de pectina / $100 \mathrm{~mL}$ de garapa). 
Foram utilizadas embalagens do tipo PET (capacidade de $500 \mathrm{~mL}$ ), incolores e transparentes, fornecidas pela empresa Braspet, localizada no município de Louveira (região de Campinas).

\subsection{MÉTODOS}

\subsubsection{Matéria-Prima}

Previamente à extração, os colmos tiveram sua casca removida (manualmente) com faca, sendo sanitizados com solução contendo 10 ppm de cloro ativo. Após 10 minutos de contato com a solução, o material foi enxaguado com água corrente tratada. Efetuou-se a sanitização da moenda empregada na operação da mesma forma.

O teor de sólidos solúveis do caldo-de-cana foi padronizado em 20Brix, valor considerado ideal pela equipe de julgadores do teste sensorial realizado preliminarmente com a garapa clarificada adicionada do suco.

Submeteu-se o caldo, extraído e padronizado, a processo parcial de clarificação-estabilização de acordo com procedimento determinado por PRATI e MORETTI (2002). O processo envolveu aquecimento do caldo em banho-maria (65ㄷ/50 min), alcalinização com $\mathrm{Ca}(\mathrm{OH})_{2}$ até pH 8,0, adição de 60 ppm de policloreto de alumínio, decantação por 45 minutos e separação do sobrenadante pelo uso de bomba de vácuo (Modelo TE-058).

\subsubsection{Produto Processado}

A Figura 1 ilustra as etapas do processamento das misturas.

\subsubsection{Análises Microbiológicas}

O produto foi analisado quanto a contagem de bolores e leveduras, contagem padrão, e número mais provável (NMP) de coliformes totais e fecais, conforme metodologia da APHA (VANDERSANT e SPLITSTOESSER, 1992). 
FIGURA 1 - FLUXOGRAMA DA OBTENÇÃO DE CALDO-DE-CANA PARCIALMENTE CLARIFICADO-ESTABILIZADO ADICIONADO DE SUCOS DE FRUTAS ÁCIDAS

Garapa parcialmente clarificada-estabilizada

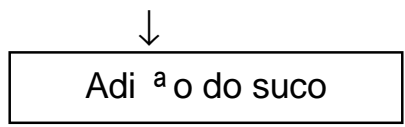

$\downarrow$

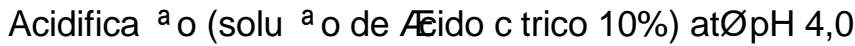

Adi $\stackrel{a}{\circ}$ do espessante $(0,05 \%$ pectina genu tipo 106$)$

Adi ${ }^{a}$ o do antioxidante $(125 \mathrm{ppm}$ de Aéido asc rbico) e do conservador (40 ppm de parabeno)

Aquecimento (pasteuriza ํㅗ $0 \quad 75 ” C / 15 \mathrm{seg}$ )

$\downarrow$

Acondicionamento (PET $500 \mathrm{~mL}$ )

Resfriamento (30"C)

$\downarrow$

Armazenamento refrigerado (4-6”C)

$\downarrow$

An/Fises 


\subsubsection{Determinações Físico-Químicas}

Foram realizadas determinações de $\mathrm{pH}$ conforme metodologia n. 42.1.04 da AOAC (1997), teor de sólidos solúveis (ํix) pela metodologia n. 37.1.15 da AOAC (1997), acidez total titulável (\% ácido cítrico) de acordo com metodologia n. 37.1.37 da AOAC (1997), relação Brix/Acidez ("ratio") pela divisão do teor de sólidos solúveis totais ("Brix) pelo valor da acidez total titulável (\%), teor de ácido ascórbico conforme método n. 43046 da AOAC (1984), modificado por BENASSI (1990), turbidez e cor instrumental (3 repetições/amostra) em espectrofotômetro para cor, modelo COLORQUEST II, marca Hunterlab. O aparelho foi calibrado para medição de transmitância (TTRAN) no sistema de cor $\operatorname{CIELAB}\left(L^{*}, a^{*}\right.$ e $\left.b^{*}\right)$, iluminante $D_{65}$ e ângulo do observador de $10^{\circ}$, empregando-se cubeta com $10 \mathrm{~mm}$ de caminho ótico para as leituras.

Os resultados de todas as determinações foram submetidos à ANOVA e teste de média de Tukey $(p \leq 0,05)$, utilizando-se o pacote "Statistica for windows 5.0" (STATSOFT, 1995). Posteriormente, elaborou-se gráfico com os dados dos teores de ácido ascórbico, ilustrando o comportamento desse componente no produto com o decorrer do período de armazenamento.

\subsubsection{Análise Sensorial}

Aplicou-se o teste de aceitação, com escala hedônica não-estruturada de 9 pontos (método afetivo). Foram avaliados os atributos aparência, cor, aroma, sabor e impressão global do produto com o objetivo de verificar sua aceitação junto ao mercado consumidor (MEILGAARD, CIVILLE e CARR, 1987; STONE e SIDEL, 1993).

A equipe sensorial foi composta por 31 julgadores não-treinados. A amostra codificada foi servida em copos plásticos descartáveis de $50 \mathrm{~mL}$, em ambiente claro (mesa branca) e na forma de blocos completos casualizados. As amostras estavam acompanhadas de biscoito, copo d'água e da ficha de avaliação (Figura 2).

Os testes sensoriais de aceitação foram realizados nos tempos 0,15 e 30 dias de armazenamento, concomitantemente às determinações microbiológicas e físico-químicas. 
FIGURA 2 - FICHA DE AVALIAÇÃO SENSORIAL PARA O TESTE DE ACEITAÇÃO DA GARAPA PARCIALMENTE CLARIFICADA-ESTABILIZADA ADICIONADA DE SUCO NATURAL DE MARACUJÁ

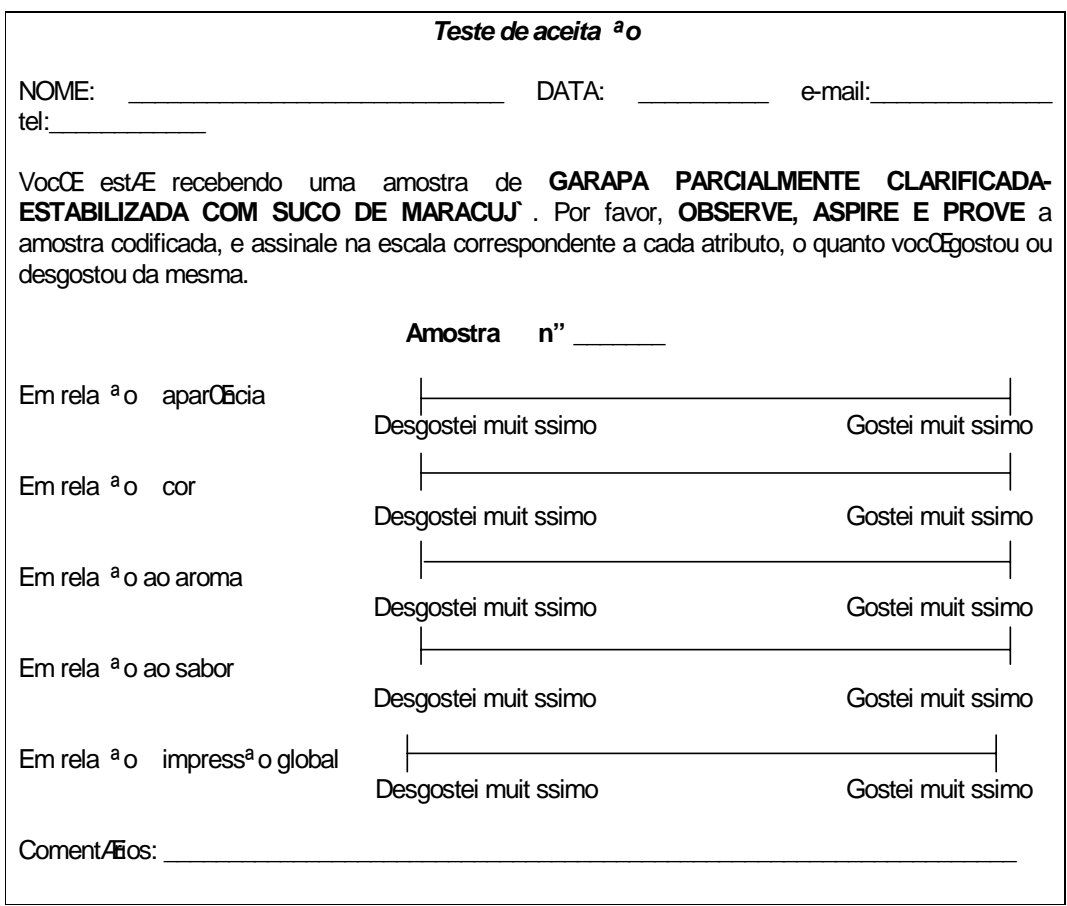

A análise sensorial permitiu estudar o efeito do tempo de armazenamento sobre a qualidade da amostra pela análise de regressão dos resultados. Também possibilitou a obtenção da diferença estatística entre as médias das notas nos diferentes tempos de armazenamento, submetendo-se os resultados à análise de variância (ANOVA) e teste de média de Tukey $(p \leq 0,05)$ (SAS, 1993).

\section{RESULTADOS E DISCUSSÃO}

\subsection{ANÁLISES MICROBIOLÓGICAS}

Na Tabela 1 constam os resultados das determinações microbiológicas 
da garapa clarificada-estabilizada adicionada de suco de maracujá. A Figura 3 ilustra a curva de regressão dos resultados (em termos de log) da contagem padrão (total) e da contagem de bolores e leveduras.

\section{TABELA 1 - RESULTADOS DAS ANÁLISES MICROBIOLÓGICAS DA GARAPA PARCIALMENTE CLARIFICADA- ESTABILIZADA ADICIONADA COM SUCO DE MARACUJÁ}

\begin{tabular}{cccc}
\hline Tempo (dias) & $\begin{array}{c}\text { Contagem total } \\
(\mathrm{UFC} / \mathrm{mL})\end{array}$ & $\begin{array}{c}\text { Contagem de bolores e } \\
\text { leveduras }(\mathrm{UFC} / \mathrm{mL})\end{array}$ & $\begin{array}{c}\text { Coliformes totais } \\
(\mathrm{NMP} / \mathrm{mL})\end{array}$ \\
\hline 0 & $2,5 \times 10^{1}$ & $3,0 \times 10^{2}$ & $<0,03$ \\
15 & $1,0 \times 10^{2}$ & $1,0 \times 10^{4}$ & $<0,03$ \\
30 & $2,0 \times 10^{3}$ & $3,3 \times 10^{6}$ & $<0,03$ \\
\hline
\end{tabular}

* Ausência de Coliformes fecais.

UFC = Unidades formadoras de colônias.

NMP = Número mais provável.

FIGURA 3 - LOG DA CONTAGEM TOTAL E CONTAGEM DE BOLORES E LEVEDURAS EM FUNÇÃO DO TEMPO DE ESTOCAGEM

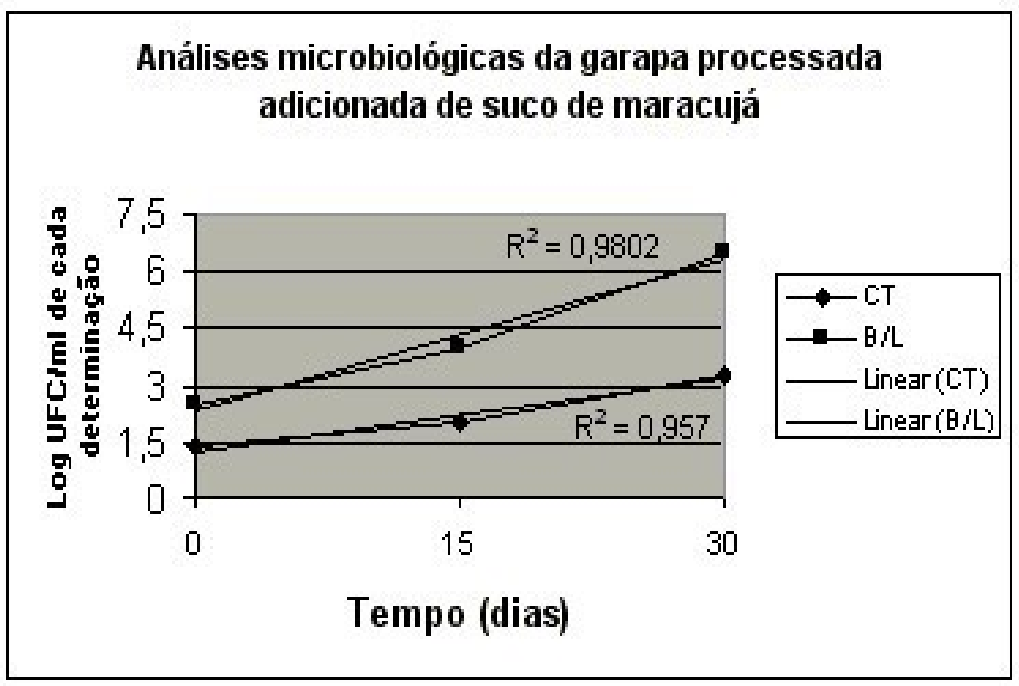


A determinação de coliformes totais na garapa parcialmente clarificadaestabilizada indicou números menores que $0,03 \mathrm{NMP} / \mathrm{mL}$ de produto, resultado enquadrado no padrão estabelecido pela resolução $\mathrm{RDC}$ n12 (BRASIL, 2001) para caldo-de-cana pasteurizado, isolado ou em mistura (máximo de $10 \mathrm{NMP} / \mathrm{mL}$ de produto).

As contagens padrão e de bolores e leveduras apresentaram carga máxima de microrganismos ao longo de 30 dias de armazenamento refrigerado (Tabela 1). Nas contagens de bolores e leveduras observouse predominância de colônias gomosas, grandes e de cor rosada, que foram isoladas por esgotamento no mesmo meio e identificadas como Rhodotorula mucilaginosa. Esse microrganismo apresenta crescimento na faixa de 0,5 a 35C e exige altos níveis de açúcar para se desenvolver. Tais condições foram oferecidas pelo produto em teste, tanto no aspecto refrigeração $\left(4-6^{\circ} \mathrm{C}\right)$ quanto no teor de açúcar da garapa (cerca de 22Brix) (PITT e HOCKING, 1999).

\subsection{DETERMINAÇÕES FÍSICO-QUÍMICAS}

A Tabela 2 apresenta os resultados das determinações físico-químicas da garapa parcialmente clarificada-estabilizada processada com suco natural de maracujá.

\section{TABELA 2 - DETERMINAÇÕES FÍSICO-QUÍMICAS DA GARAPA PARCIALMENTE CLARIFICADA-ESTABILIZADA PROCESSADA COM SUCO DE MARACUJÁ}

\begin{tabular}{|c|c|c|c|}
\hline Determina I es & Tempo 0 & Tempo 15 & Tempo 30 \\
\hline $\mathrm{pH}$ & $3,93 \pm 0,01^{b}$ & $3,96 \pm 0^{a}$ & $3,97 \pm 0^{a}$ \\
\hline $\begin{array}{l}\text { Teor de s lidos soløeis ("Brix) a } \\
20 " \mathrm{C}\end{array}$ & $19,70 \pm 0,2^{a}$ & $19,00 \pm 0,1^{b}$ & $18,60 \pm 0,06^{c}$ \\
\hline Acidez total titul/trel (\% Acido c trico) & $0,294 \pm 0,003^{a}$ & $0,275 \pm 0^{b}$ & $0,275 \pm 0,003^{b}$ \\
\hline Rela a o Brix/Acidez ( ratio ) & $67,93 \pm 0,4^{b}$ & $69,09 \pm 0,36^{a}$ & $67,64 \pm 0,99^{b}$ \\
\hline Teor de Aeido asc rbico $(\mathrm{mg} / 100 \mathrm{~g})$ & $13,18 \pm 0,23^{a}$ & $11,95 \pm 0,24^{b}$ & $10,04 \pm 0,24^{c}$ \\
\hline Turbidez (\%) & $87,80 \pm 0,24^{b}$ & $87,83 \pm 0,02^{b}$ & $88,62 \pm 0,64^{a}$ \\
\hline Cor L & $85,43 \pm 0,11^{a}$ & $84,95 \pm 0,06^{b}$ & $84,12 \pm 0,33^{c}$ \\
\hline Cor a & $1,69 \pm 0,04^{c}$ & $1,79 \pm 0,02^{b}$ & $1,98 \pm 0,06^{a}$ \\
\hline Cor b & $38,94 \pm 0,07^{b}$ & $37,08 \pm 0,10^{b}$ & $37,02 \pm 0,16^{b}$ \\
\hline
\end{tabular}

Médias seguidas pela mesma letra minúscula em cada linha não diferem entre si a $\mathrm{p} \leq 0,05$.

* Médias de 3 repetições e respectivos desvios-padrão. 
O teor de vitamina $\mathrm{C}$ diminuiu com o tempo de armazenamento devido a fatores como temperatura, oxigênio e luz, tendo todos os tempos diferido estatisticamente entre si. A análise de regressão (Figura 4) também mostrou correlação linear significativa $(p \leq 0,05)$ entre o tempo de armazenamento e o teor de ácido ascórbico.

\section{FIGURA 4 - ANÁLISE DE REGRESSÃO CONTENDO A EQUAÇÃO DA RETA E O VALOR DE R ${ }^{2}$ PARA AS MÉDIAS DO TEOR DE ÁCIDO ASCÓRBICO}

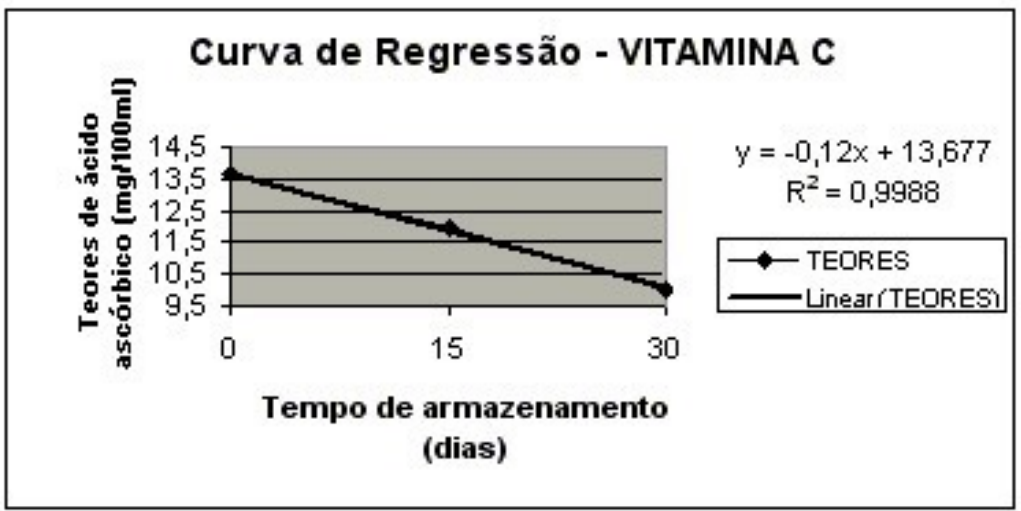

A perda total de vitamina $\mathrm{C}$ em relação ao teor adicionado foi de $19,7 \%$ (de $12,5 \mathrm{mg} / 100 \mathrm{~mL}$ para $10,04 \mathrm{mg} / 100 \mathrm{~mL}$ ). Após o processamento não houve diminuição no nível de vitamina $C$ pela presença desse constituinte em certa quantidade na matéria-prima, mas entre os tempos 0 e 15 chegou a 9,3\%. A vitamina $C$ pode ser degradada por reações enzimáticas e não-enzimáticas. Como o produto foi submetido a tratamento térmico é pouco provável que a ação enzimática tenha ocorrido. As reações não-enzimáticas (escurecimento não-enzimático) podem ser aeróbicas ou anaeróbicas. Em presença de oxigênio o ácido ascórbico é degradado a ácido dicetogulônico. Já sob anaerobiose é hidrolisado por diversas reações até formar dióxido de carbono e furfural, que se polimeriza formando melanoidinas. A degradação anaeróbica do ácido ascórbico é acelerada na faixa de $\mathrm{pH}$ 3,0 a 4,0 e em presença de açúcares simples (HENSHALL, 1981; OLIVA, 1995). Em qualquer situação, a degradação desse constituinte 
depende de fatores como concentração da vitamina, $\mathrm{pH}$, conteúdo de oxigênio, exposição à luz, temperatura de estocagem e processamento (OLIVA, 1995). ARAÚJO (1995) ainda cita que a oxidação da vitamina $\mathrm{C}$, via enzimática ou não, é acelerada pela presença de íons metálicos como $\mathrm{Cu}^{++}$e $\mathrm{Fe}^{++}$.

Os fatores que mais colaboraram para a degradação do ácido ascórbico no produto foram a luz, pois usou-se embalagem transparente, e a incorporação de oxigênio durante o processamento.

Os teores de acidez diminuíram durante o período de estocagem, provavelmente como conseqüência do decréscimo no teor de ácido ascórbico.

Falhas na padronização do Brix do caldo-de-cana podem ter influenciado a grande variação no teor de sólidos solúveis, que justificam os diferentes valores da relação Brix/Acidez ("ratio") encontrados no decorrer do período de estocagem.

Os valores de $\mathrm{pH}$ apresentaram aumento até o final do período de estocagem, provavelmente pela redução nos teores de ácido ascórbico que contribui para a acidez da bebida.

A turbidez apresentou ligeiro aumento durante o armazenamento devido ao surgimento de substâncias em suspensão, o que poderia ser explicado pela pequena proporção de espessante adicionado.

Os valores dos elementos de cor (Tabela 2) revelaram que houve ligeira redução de luminosidade, ou seja, a amostra escureceu pela oxidação do ácido ascórbico. A tonalidade vermelha ( $\underline{b})$ diminuiu e a amarela (a) intensificou-se. Durante todo o período de armazenamento, a amostra manteve sua luminosidade intensa e cor amarelada.

\subsection{ANÁLISE SENSORIAL}

Apenas os resultados dos atributos cor, sabor e impressão global das amostras (mais relevantes para a pesquisa) foram considerados na análise de regressão durante o período de armazenamento e teste de Tukey a $5 \%$ de probabilidade (Tabela 3 ). 


\section{TABELA 3 - DIFERENÇAS ESTATÍSTICAS ENTRE AS MÉDIAS DAS NOTAS DOS ATRIBUTOS COR, SABOR E IMPRESSÃO GLOBAL NO DECORRER DO PERÍODO DE ESTOCAGEM}

\begin{tabular}{cccc}
\hline $\begin{array}{c}\text { TEMPO } \\
\text { (dias) }\end{array}$ & $\begin{array}{c}\text { MØdias notas } \\
\text { COR }\end{array}$ & $\begin{array}{c}\text { MØdias notas } \\
\text { SABOR }\end{array}$ & $\begin{array}{c}\text { MØdias notas } \\
\text { IMPRESS }^{\wedge} \text { O GLOBAL }\end{array}$ \\
\hline 0 & $7,3^{\mathrm{a}}$ & $7,8^{\mathrm{a}}$ & $7,7^{\mathrm{a}}$ \\
15 & $7,3^{\mathrm{a}}$ & $7,5^{\mathrm{ab}}$ & $7,7^{\mathrm{a}}$ \\
30 & $6,7^{\mathrm{b}}$ & $7,3^{\mathrm{b}}$ & $7,4^{\mathrm{b}}$ \\
\hline
\end{tabular}

Médias seguidas pela mesma letra minúscula em cada coluna não diferem entre si a $\mathrm{p} \leq 0,05$.

A Figura 5 evidencia que não houve correlação linear significativa $(a p \leq 0,05)$ entre o tempo de armazenamento e o atributo cor. Apesar disso, os dados estatísticos (que constam da Tabela 3 ) revelaram ligeira redução no atributo cor, sendo a nota atribuída aos 30 dias estatisticamente diferente das demais.

FIGURA 5 - ANÁLISE DE REGRESSÃO CONTENDO A EQUAÇÃO DA RETA E O VALOR DE R² PARA O ATRIBUTO COR

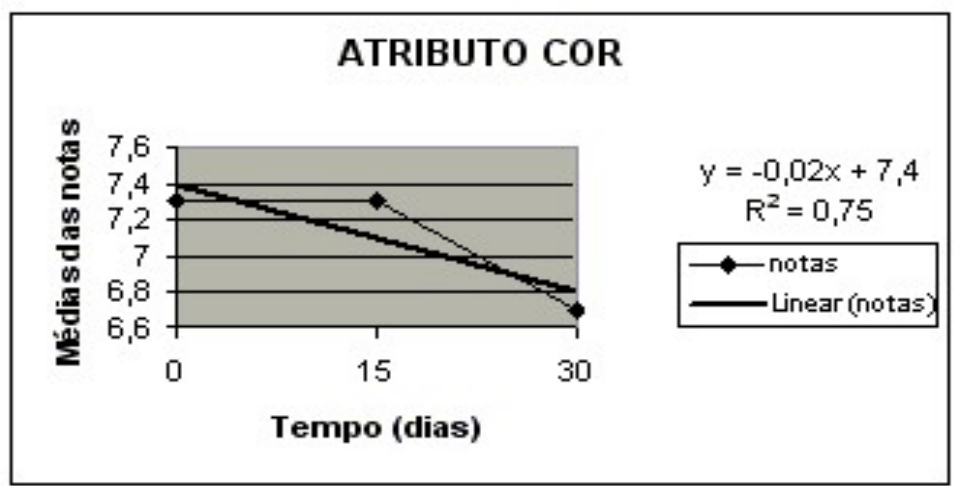

A análise da Figura 6 revelou correlação linear significativa $(a p \leq 0,05)$ entre o tempo de armazenamento e o sabor da amostra. Os resultados estatísticos (Tabela 3) indicam que as médias das notas dos tempos 0 e 30 diferiram significativamente entre si, mas não da nota média no tempo 15. Assim, houve redução na qualidade do sabor durante o período de estocagem. 
FIGURA 6 - ANÁLISE DE REGRESSÃO CONTENDO A EQUAÇÃO DA RETA E O VALOR DE $\mathbf{R}^{2}$ PARA O ATRIBUTO SABOR

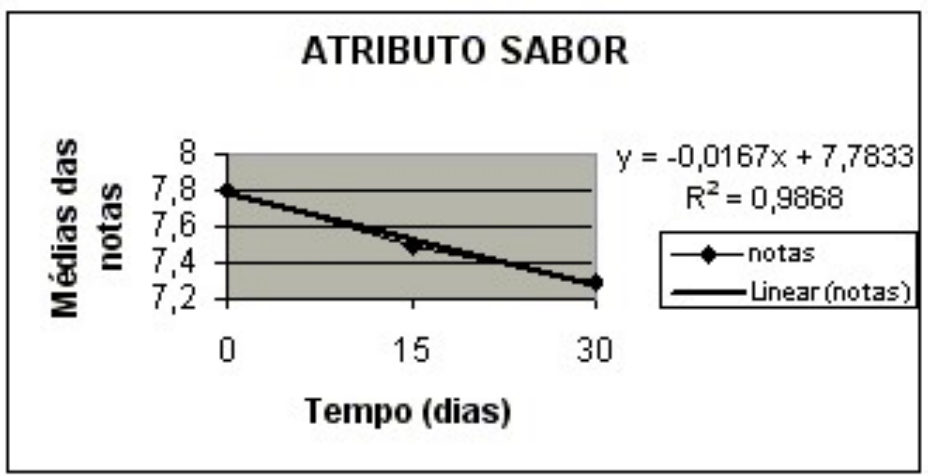

Não foi verificada correlação linear significativa $(p \leq 0,05)$ entre o tempo de armazenamento e a impressão global da bebida testada (Figura 7). Já a Tabela 3 mostra que a nota atribuída no tempo 30 foi significativamente inferior às notas referentes aos tempos 0 e 15 dias, evidenciando redução na qualidade do atributo impressão global durante o armazenamento.

FIGURA 7 - ANÁLISE DE REGRESSÃO CONTENDO A EQUAÇÃO DA RETA E O VALOR DE ${ }^{2}$ PARA O ATRIBUTO IMPRESSÃO GLOBAL

\section{ATRIBUTO IMPRESSÃO GLOBAL}
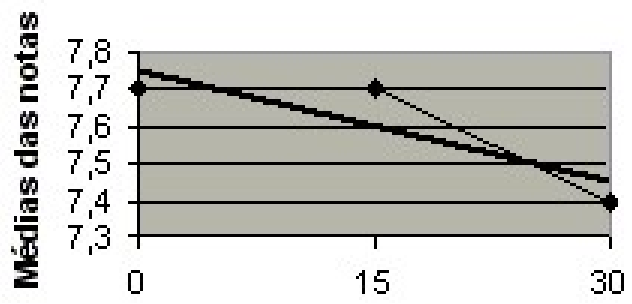

$$
\begin{gathered}
y=-0,01 x+7,75 \\
R^{2}=0,75
\end{gathered}
$$

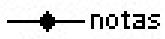
Linear (notas)

Tempo (dias) 


\section{CONCLUSÃO}

O estudo das condições microbiológicas do produto indicou predominância do grupo de microrganismo levedura do tipo Rhodotorula mucilaginosa. Sua carga limite $\left(10^{6} \mathrm{UFC} / \mathrm{mL}\right.$ de produto $)$ determinou tempo de estocagem de 15 dias em temperatura entre 4 e 6으.

O mistura de garapa com suco de maracujá não revelou notáveis alterações organolépticas, embora tenha apresentado contagens padrão e de bolores e leveduras da ordem de $10^{3}$ e $10^{6}$, respectivamente, ao final do período de armazenamento. Os resultados das determinações de coliformes totais enquadraram-se no limite estabelecido pela legislação vigente durante toda a estocagem.

As variações ocorridas nas determinações físico-químicas foram consideradas perfeitamente normais para o produto em questão. $O$ teor de ácido ascórbico sofreu perda de apenas $20 \%$ (em relação ao que foi adicionado) até o final da estocagem refrigerada (4-6으 em garrafas PET.

A bebida elaborada pela mistura de garapa parcialmente clarificadaestabilizada com suco de maracujá, armazenada sob refrigeração (4$\left.6^{\circ} \mathrm{C}\right)$ e acondicionada em garrafas PET, mantém qualidade microbiológica e sensorial satisfatória até 15 dias após o processamento.

\section{ABSTRACT}

\section{SHELF-LIFE STUDY OF A BEVERAGE ELABORATE BY BLEND OF PARTIALLY CLARIFIED-STABILIZED SUGAR-CANE JUICE AND NATURAL PASSION FRUIT JUICE}

The objective of this research was to study the shelf-life of a product elaborated with sugar cane juice, partially clarified-stabilized, and passion-fruit juice (5\%). The blend was added of antioxidant, preservative and thickener in pre-established concentration. After pasteurization the product was refrigerated in polyethylene teraftalate (PET) bottles and stored for 1 month period under refrigeration. Microbiological determinations (Standard Count, Mould and Yeasts Count, Total and Faecal Coliforms), physico-chemical (Brix, $\mathrm{pH}$, acidity, relation Brix/acidity, ascorbic acid content, turbidity) and sensorial were accomplished. The results of sensorial analysis, considered the more relevant for the research, indicated that the product (blend of sugar-cane juice partially clarified/stabilized with passion fruit juice) may be elaborated and commercialized until 15 days under refrigeration, 
because the conditions of the process allowed the maintenance of microbiological and sensorial quality. Ascorbic acid content maintained a good level until the end of storage, with lost of only $20 \%$ in relation to the concentration added.

KEY-WORDS: SUGAR-CANE; PASSION FRUIT; FRUIT JUICE; SENSORY ANALYSIS.

\section{REFERÊNCIAS}

1 ARAÚJO, J.M.A. Química de alimentos: teoria e prática. Viçosa: Universidade Federal de Viçosa, 1995. 335 p.

2 AOAC. Association of Official Analytical Chemists. Official methods of analysis of AOAC Internacional. $12^{\text {th }}$ ed. Washington, 1984. p.844-845.

3 AOAC. Association of Official Analytical Chemists. Official methods of analysis of AOAC Internacional. $16^{\text {th }}$ ed. Washington, 1997.

4 BENASSI, M.T. Análise dos efeitos de diferentes parâmetros na estabilidade de vitamina $\mathbf{C}$ em vegetais processados. $1990.159 \mathrm{p}$. Dissertação (Mestrado) - Faculdade de Engenharia de Alimentos/UNICAMP.

5 BRASIL. Ministério da Saúde. Agência Nacional de Vigilância Sanitária. Resolução RDC n 12, 2 jan. 2001. Diário Oficial [da] República Federativa do Brasil, Brasília, p.17, 2001. Seção 1.

FRANCO, B.D.G.M.; LANDGRAF, M. Microbiologia dos alimentos. São Paulo: Atheneu, 1996. $182 \mathrm{p}$.

7 GAVA, A.J. Emprego de conservadores químicos em alimentos. Boletim da Sociedade Brasileira de Ciência e Tecnologia de Alimentos, v.13, n.3, p.183-194, jul./set. 1984.

8 GARRUTI, D.S. Contribuição ao estudo da estabilização física do suco de maracujá integral (Passiflora edulis f. flavicarpa). Campinas 1989. 198 p. Dissertação (Mestrado) - Faculdade de Engenharia de Alimentos/UNICAMP.

9 HENSHALL, J.D. Ascorbic acid in fruit juices and beverages. In: COUNSELL, J.N.; HORNIG, D.H. Vitamin C: ascorbic acid. London: Applied Science Publishers, 1981. Cap.8.

10 LEITÃO, M.F.F. Microbiologia de sucos e produtos ácidos. Boletim do Instituto de Tecnologia de Alimentos, n.33, p.9-42, mar. 1973.

11 MEDINA, J.C.; GARCIA, J.L.M.; LARA, J.C.; TOCCHINI, R.P.; HASHIZUME, T.; MORETTI, V.A.; CANTO, W.L. Maracujá: da cultura ao processamento e comercialização. Campinas: ITAL/Governo do Estado de São Paulo, 1980. 
207 p. (Manual Técnico - Série Frutas Tropicais, n.9)

12 MEILGAARD, M.; CIVILLE, G.V.; CARR, B.T. Sensory evaluation techniques. New YorK: CRC Press, 1987. 281 p.

13 OLIVA, P.B. Estudo do armazenamento da acerola in natura e estabilidade do néctar de acerola. Campinas, 1995. 103 p. Dissertação (Mestrado) - Faculdade de Engenharia de Alimentos/UNICAMP.

14 PITT, J.I.; HOCKING, A.D. Fungi and food spoilage. Gaithersburg: Aspen Publication, 1999. Cap.10.

15 PRATI, P.; MORETTI, R.H. Desenvolvimento de processo para clarificação de caldo-de-cana para consumo. In: CONGRESSO BRASILEIRO DE CIÊNCIA E TECNOLOGIA DE ALIMENTOS, 18., 2002, Porto Alegre. Anais... Porto Alegre: UFGRS, 2002. 1 CD-ROOM.

16 PRATI, P.; MORETTI, R.H.; CARDELLO, H.M. Estudo de três diferentes concentrações de ácido ascórbico na qualidade sensorial de garapa clarificada estocada sob refrigeração. In: BRAZILIAN MEETING ON CHEMISTRY OF FOOD AND BEVERAGES, 4., 2002, Campinas. Anais... Campinas: UNICAMP, 2002. 1 CD-ROOM.

17 SAS Institute. SAS user's guide: statistics. Cary, 1993.

18 SOUZA, A.C.G.; SANDI, D. Industrialização. In: BRUCKNER, C.H.; PICANÇO, M.C. Maracujá: tecnologia de produção, pós-colheita, agroindústria e mercado. Porto Alegre: Cinco Continentes, 2001. Cap.12.

19 STASOFT Inc. Statistic for windows: version 5.0. Tulsa, 1995.

20 STONE, H.; SIDEL, J.L. Sensory evaluation practices. New York: Academic Press, 1993. 338 p.

21 VANDERSANT, C.; SPLITSTOESSER, F.O. Compendium of methods for the microbiological examination of foods. $3^{\text {rd. }}$ ed. Washington, D.C.: American Health Association (APHA), 1992. 1219 p.

\section{Agradecimentos}

Ao Conselho Nacional de Desenvolvimento Científico e Tecnológico (CNPq) e à Fundação de Amparo à Pesquisa do Estado de São Paulo (FAPESP) pelo apoio técnico, científico e financeiro oferecidos para a realização desta pesquisa. 